\title{
Passing the Gavel
}

It is with a sense of satisfaction and some trepidation that I have recently succeeded Eric Hartwig as TOS president. Eric has devoted a great deal of his time and talent to TOS over the past two years, and there are positive results to show for them. He represented TOS in negotiations leading to the highly successful TOS/ASLO Ocean Research Conference in February 2004 and he was instrumental in guiding challenging negotiations and planning for the joint AGU/ASLO/TOS Ocean Science Meetings in 2006 and 2008. During his tenure, Oceanography has been published on a regular basis, a TOS Fellows Program has been started, membership has increased, and the Society's financial picture has improved. Thank you, Eric!

With the passing of the gavel, Eric moves to the position of Past President, succeeding Jim Yoder. Both Jim and Ellen Druffel have fulfilled their terms on the TOS Council and deserve acknowledgement and thanks for their services and contributions to the Society.

In looking ahead, plans are well underway for the TOS International Ocean Research Conference, to be held at UNESCO Headquarters in Paris from June 6-10, 2005. Oscar Schofield and Catherine Jeandel are co-chairing the event. Tim Jickells, Bob Anderson, Don Anderson, Patrick Gentien, Temel Oguz, James Murray, Linda Medlin, and Lee Kerkhof are on the steering committee. They strongly encourage submission of posters, and participation in the conference. Further information may be obtained from the TOS web site (http://www.tos.org).

Ellen Kappel, editor of Oceanography, has given the magazine a face lift making it more eye-catching and easier to read. She has a number of special issues lined up and several unsolicited manuscripts. But she is always looking for additional sponsors, themes, and authors. You can communicate with Ellen either through the TOS web site or at ekappel@geo-prose.com.

And if you participated in the recent TOS elections, you will have noticed the totally redesigned TOS web site. An approved change in the Society's By-Laws last year now allows elections to be conducted electronically through the web page. The web areas devoted to the magazine are full of new information-new author guidelines and an updated style guide. We are still working on posting pdf files of back issues; there's a fair amount of content on those pages already. The ability to access back issues of Oceanography is one of the requests we have heard most often from members.

Looking ahead, I hope to work with the TOS Council over the next two years to make the Society more relevant and of greater value to its membership. The origins of TOS are rooted in bringing together and recognizing individuals from all fields of oceanography, representing the broad interests of members in research, engineering, industry, policy, and education. The broadly interdisciplinary nature and interrelatedness of the field has certainly been highlighted recently through a special issue of a national news magazine devoted to the oceans, through the report of the U.S. Commission on Ocean Policy, and the responses to the report (for discussion see Briscoe et al., this issue). The critical importance of different oceanographic sectors being able to plan and work together is also exemplified by increasing interests and international planning activities for new ocean and Earth observing systems. With its award-winning magazine, interdisciplinary focus, and diverse membership, TOS is well positioned to facilitate the communication and exchange of ideas and to provide a constituency for consensus-building across all disciplines of oceanography.

The success of a professional society really depends on its membership. As all the TOS presidents have done before me, I ask you to reach out to colleagues, friends, and students and urge them to consider membership in TOS. TOS recognizes and celebrates the full range of oceanographic interests and welcomes everyone having an interest in oceanography.

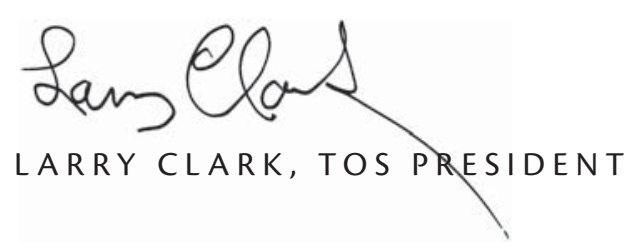

